\title{
A NEW BRANCH OF THE ANIO NOVUS AQUEDUCT (ROME, ITALY) REVEALED BY ARCHAEOLOGY AND GEOPHYSICS
}

\author{
D. Blanco ${ }^{1}$, L. Alessandri ${ }^{2}$, V. Baiocchi ${ }^{3}$, A. De Laurenzi ${ }^{4}$, F. Monti ${ }^{3}$, I. Nicolosi ${ }^{5}$, S. Urbini ${ }^{5}$, F. Vatore ${ }^{3}$ \\ ${ }^{1}$ Archeogeos, Rome, Italy - archeogeos@gmail.com \\ ${ }^{2}$ Groningen Institute of Archaeology, University of Groningen, Groningen, Netherlands - 1.alessandri@gmail.com \\ ${ }^{3}$ Sapienza University of Rome, DICEA, Rome, Italy - (valerio.baiocchi, felicia.monti, felicia.vatore)@uniroma1.it \\ ${ }^{4}$ Soprintendenza Speciale di Roma, Archeologia Belle Arti Paesaggio, Roma, Italy - angelina.delaurenzi@beniculturali.it \\ ${ }^{5}$ Istituto Nazionale Geofisica e Vulcanologia, Rome, Italy (iacopo.nicolosi, stefano.urbini)@ingv.it
}

KEYWORDS: Ground Penetrating Radar, Electrical Resistivity Tomography, Photogrammetry, Roman aqueducts, Archaeology, Structure From Motion

\begin{abstract}
:
The area south-east of Rome is characterised by the presence of several roman aqueducts which brought water to the eternal city from the Apennine and Alban Hills springs. In the last 40 years, several pieces of evidence about these aqueducts were acquired during the realisation of archaeological test trenches before building activities. In 2019, a small branch of a subterranean aqueduct unknown to the Latin sources was unearthed in Via dei Sette Metri. Here we show that this aqueduct is a lateral branch of the Anio Novus, a major imperial aqueduct built between 38 and $52 \mathrm{CE}$. To achieve this result, we employed detailed photogrammetric restitution of the new aqueduct and an integrated geophysical survey focused in the area where the Anio Novus was supposed to pass. Electrical Resistivity Tomography (ERT) and Ground Penetrating Radar (GPR) methods were used to reconstruct aqueduct paths and their relative heights. Different light conditions were tested during the picture acquisition step to determine the best practice in the photogrammetric restitution. The results obtained in this study confirmed the great effectiveness of the integration between geophysical investigation methods and the modern archaeology approach in detecting buried ancient structures.
\end{abstract}

\section{INTRODUCTION}

In 2019, test trenches to evaluate the presence of archaeological evidence were carried out in Via dei Sette Metri, Rome. The investigation led to the discovery of a Republican road cut into the tufa subsoil and a stretch of a later roman subterranean aqueduct. Several Roman aqueducts in the area were already reported, bringing water from the Alban Hills (Aqua Tepula and Aqua Iulia) and the Aniene valley (Anio Vetus, Aqua Marcia, Aqua Claudia and Anio Novus) (Ashby, 1935; Lanciani, 1880). In particular, the imperial aqueduct Anio Novus was running quite close to the excavation area. We thereby want to test the hypothesis that the Sette Metri aqueduct could have been a lateral branch of the Anio Novus, to possibly bring water to a nearby villa. To tackle this issue, we reconstruct the paths of both the aqueducts using the photogrammetric technique and a geophysical survey purposely carried out in the nearby fields. The results of this research are presented below.

\subsection{The Anio Novus path}

In the area, a puteus and a portion of the subterranean stretch of the Anio Novus were found just near the modern Anagnina road, near the number 332 (Blanco and Sebastiani Del Grande, 2019, p. 163) (Fig. 1, 1). The intrados of the specus was $310 \mathrm{~cm}$ below the surface. Other stretches of the aqueduct were reported in 1972 between Via dei Sette Metri and via del Casale Santarelli (Fig. 1, 2). The information about these finds is unfortunately incomplete. In 2004/2005, another stretch was unearthed between Via dei Sette Metri and via della Tenuta del Casalotto at a depth of about $130 \mathrm{~cm}$ from the surface. The specus was $102 \mathrm{~cm}$

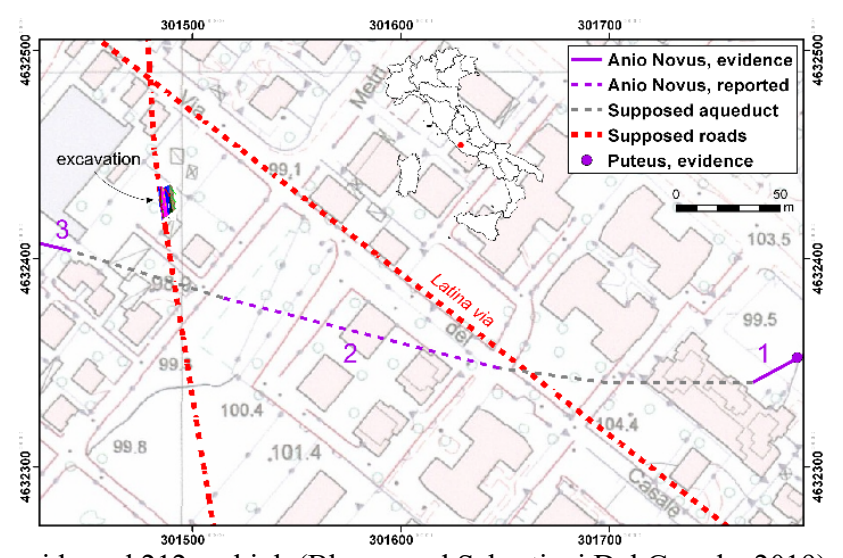

wide and $212 \mathrm{~cm}$ high (Blanco and Sebastiani Del Grande, 2019)

Figure 1. The excavation area.

(Fig. 1, 3).

\section{METHODS}

\subsection{The excavation}

All the heights are orthometric. The stratigraphic excavation took place between December 2019 and November 2020, with a long interruption due to the SARS-CoV-2 pandemic. The excavation was carried out with the aid of a digging machine until the archaeological or geological layers were reached. Later, the archaeological layers were manually excavated. The aqueduct has been cut open for a very short stretch to investigate a portion 


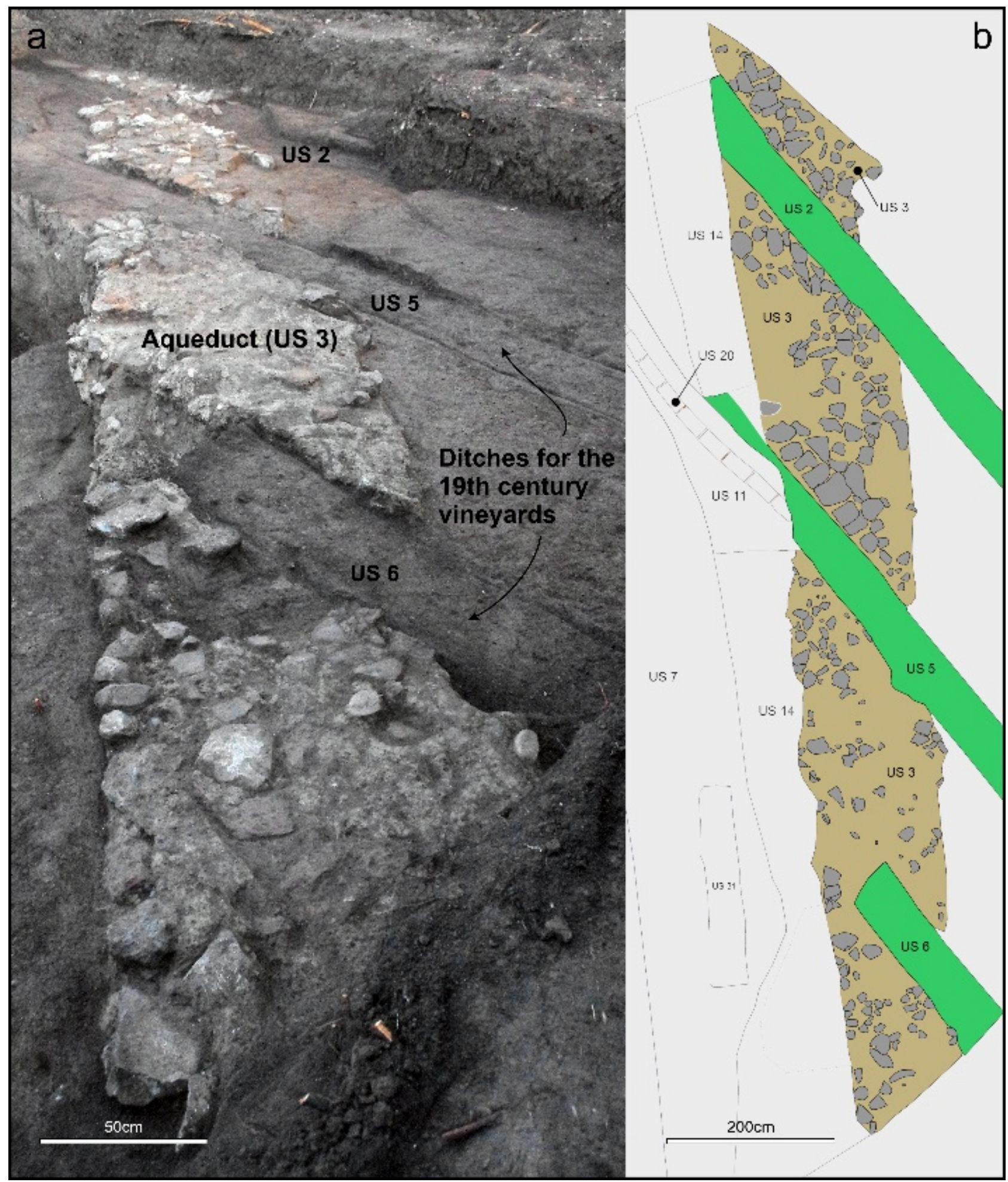

Figure 2. Picture (a) and map (b) of the Sette Metri aqueduct. US, stratigraphic unit.

of the interior deposits. With few exceptions, among which the residual internal deposit of the specus, the archaeological layers have been completely removed.

\subsection{The photogrammetric model}

The aqueduct profiles were drawn using terrestrial photogrammetry based on SFM techniques (Ullman and Brenner, 1979), currently the subject of several studies in the literature
(Alessandri et al., 2020; Caroti et al., 2015; Masiero et al., 2019). Different portions of the site (as is often the case for areas lower than the ground level) have different insolation conditions which also depends on the acquisition time. For this reason, the samples were taken at different times and therefore with different sun heights. Two surveys were compared which were carried out with a professional camera type Pentax K-x SLR and a mobile phone type Xiaomi Mi Note 10 with 108 megapixels optics, respectively. The surveys were framed by differential GNSS 


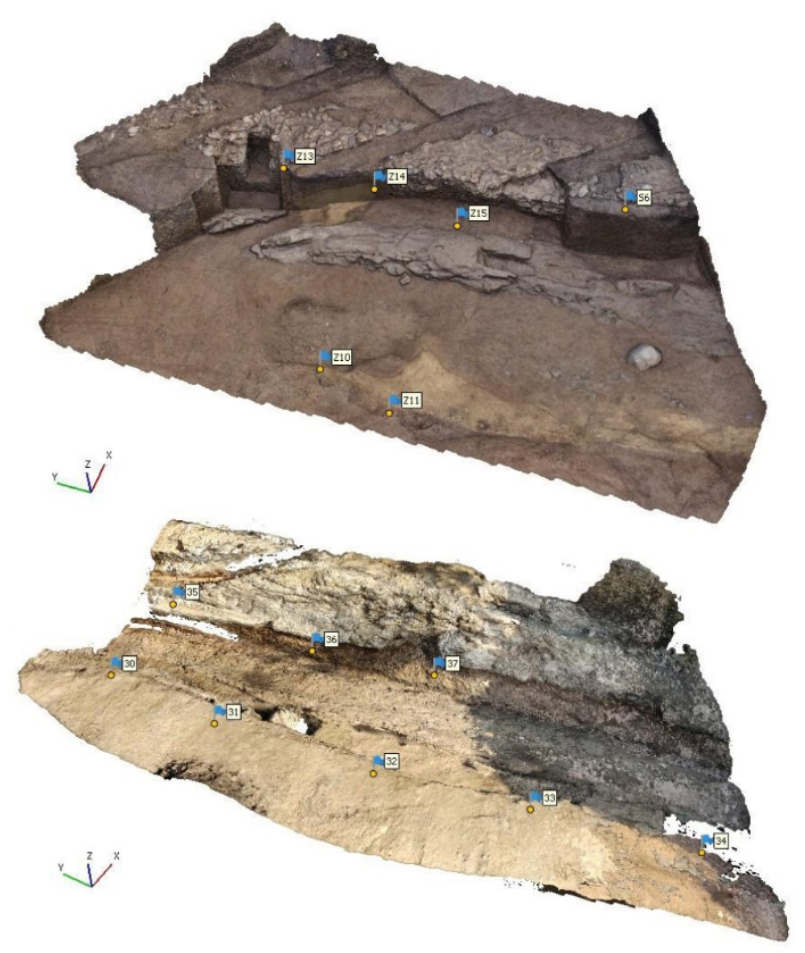

Figure 3. The two photogrammetric 3D models of the Sette Metri aqueduct. The pictures were taken at two different times during the excavation.

surveys using classic dual-frequency GNSS GPS/Glonass receivers and (for comparison) using the U-Blox fourconstellation card (GPS, GLONASS, Galileo, Beidou). This card is very compact and inexpensive and can be extremely useful in the framework of the archaeological surveys since it can be easily transported and can give good results even in depressed sites (such as excavations) thanks to its ability to use four constellations. However, in our test, the four constellations could not be all used because the CORS network of the Lazio Region only manages GPS and Glonass ("Rete GNSS della Regione Lazio," 2018). The comparison between the two survey modes provided differences of a few centimetres, probably due to the limited number of decimal digits available in U-blox's proprietary software, which were probably intentionally limited. The ellipsoidal elevations obtained were converted into orthometric elevations using the Italgeo 05 geoid model, which is accredited with an accuracy of approximately $2.5 \mathrm{~cm}$ (Barzaghi et al., 2007). The transformation was carried out using Geotrasformer software, which adopts the official transformations provided for the interpolation of the model itself (Baiocchi et al., 2017).

\subsection{The GPR survey}

The GPR method is based on the reflection of electromagnetic waves generated at the interface between media characterized by differences in dielectric properties. The soil dielectric properties are strictly related to lithology, porosity, and moisture/water saturation, and are fundamental in GPR signal propagation and attenuation. In some soil types, such as those characterized by a high content of mineralized water (i.e., clay) or those derived from volcanic rocks or otherwise high in iron or metallic content, conduction and dielectric effects can cause the absorption of EM radiation, reducing the effectiveness of the GPR method.

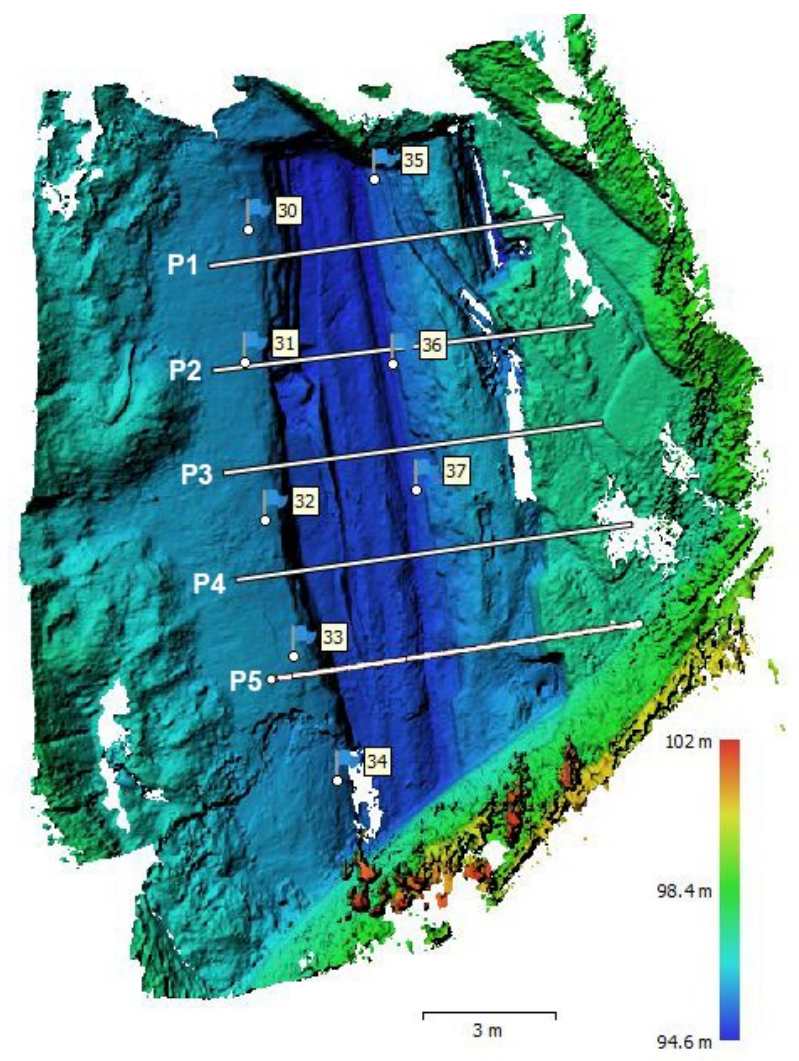

Figure 4. The DEM extracted from the 3D model of the Sette Metri aqueduct

The resolution of the technique mainly depends on the signal frequencies generated by the transmitting antenna but higher frequencies correspond also to high signal attenuations. Consequently, the use of different antenna frequencies allows investigating the subsoil at different depths and with different resolutions.

Considering the target dimensions, and its expected burial depth, in this study we used a GSSI Sir4000 instrument equipped with a $200 \mathrm{MHz}$ monostatic antenna.

The survey consisted of a 3D grid acquisition (43x17m; Fig. 6) made up of lines at a $1 \mathrm{~m}$ distance.

A survey wheel and a differential GPS (Topcon GB1000) acquisition were used to obtain a more rigorous determination of scan positions along with the 3D survey.

The main acquisition settings were as follows: range, $170 \mathrm{~ns}$; vertical sampling, 512; horizontal sampling, $80 \mathrm{scan} / \mathrm{m}(120$ scan/s); 32 bits dynamic. Data post-processing included the application of vertical and horizontal band-pass filters, deconvolution, gain equalization and migration.

Time to depth conversion of radargrams was performed through the analysis of hyperbola diffractions which pointed out an averaged electromagnetic wave speed of about $0.071 \mathrm{~m} / \mathrm{ns}(\varepsilon=$ 17.8 ) in the weathered shallow soil.

Considering the speed constant along with the acquisition range, the investigated depth corresponds to about $5.3 \mathrm{~m}$.

\subsection{The ERT survey}

We carried out an ERT survey to investigate the subsurface structures as a function of their electrical features. We acquired three 2D parallel profiles using a SYSCAL Pro 10 channel resistivity-meter, equipped with 48 electrodes (IRIS Instruments). The instrument was configured to inject a square wave signal for $250 \mathrm{~ms}$. Each profile was acquired using 48 steel electrodes spaced 0.5 meters apart; both dipole-dipole and 

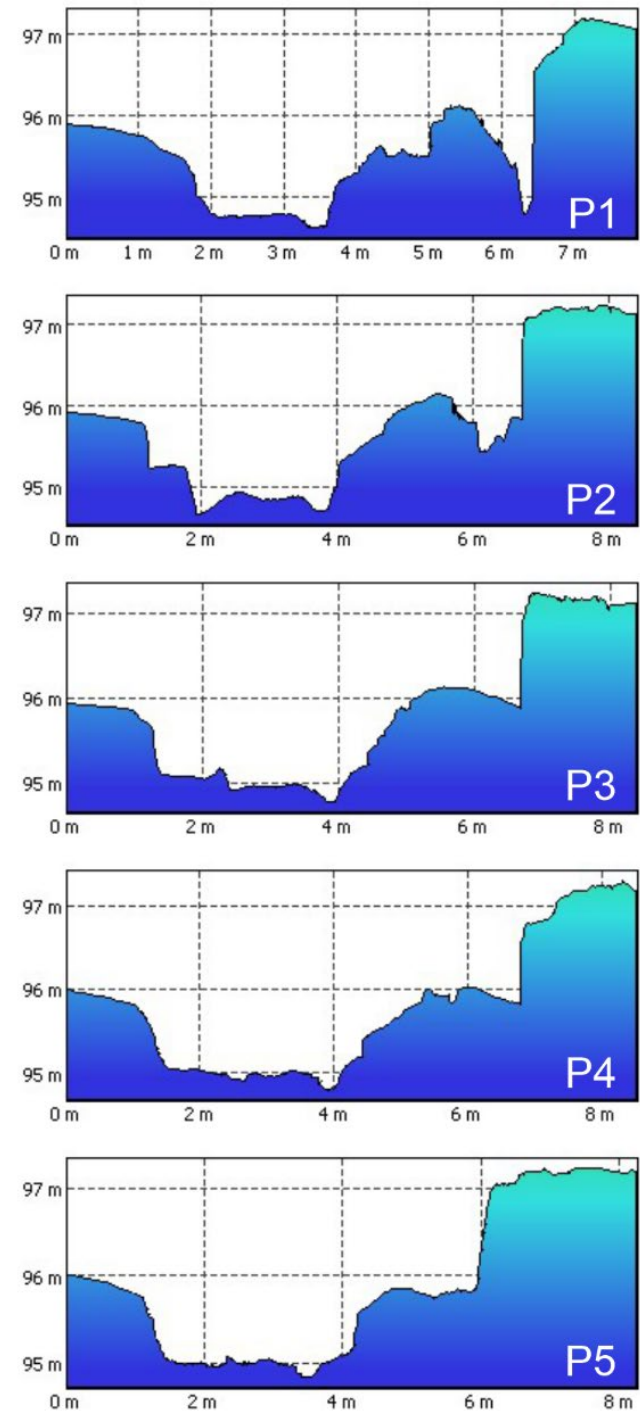

Figure 5. The profiles of the Sette Metri aqueduct. Refer to figure 4 for the profile lines.

Wenner array configurations were applied aimed at obtaining good vertical and horizontal resolution of the subsurface resistivity contrasts (Loke, 2012). The profile length of 23.5 meters provided a pseudo exploration depth of 4 meters each.

The distance between profile lines is about 6 meters. An appropriate electrical coupling between adjacent electrodes and soil was achieved recording a resistivity ground contact of about $1 \mathrm{kOhm} * \mathrm{~m}$.

To obtain true resistivity values from the measured apparent resistivity data, we used the smoothness-constrained least squares method considering models with an infinite perpendicular extension along the profile strike (Constable et al., 1987; deGroot-Hedlin and Constable, 1990; Morelli and Labrecque, 1996).

\section{RESULTS}

\subsection{The Sette Metri aqueduct}

The aqueduct (Fig. 2) has been unearthed for about $13,5 \mathrm{~m}$. It is about $145-175 \mathrm{~cm}$ wide at the top and it is about $200 \mathrm{~cm}$ high. The specus is $60 \mathrm{~cm}$ wide and $140 \mathrm{~cm}$ high. At the bottom of the specus, a small ditch parallel to the walls was excavated, $35 \mathrm{~cm}$ wide and $20 \mathrm{~cm}$ high, to make the water flow. The height

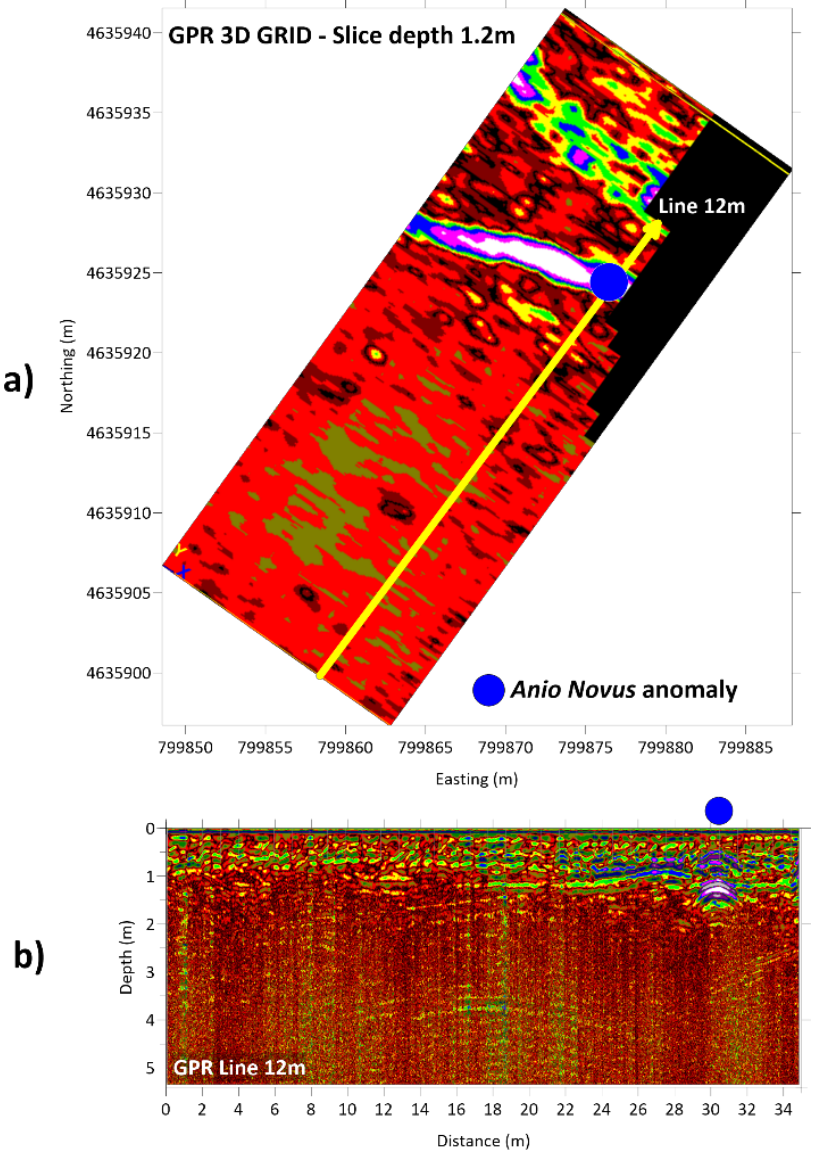

Figure 6. Anio Novus GPR anomaly; a) 3D Slice $1.2 \mathrm{~m}$ depth; b) GPR Profile $X=12 \mathrm{~m}$

difference between the aqueduct top surface and the ditch bottom is $209 \mathrm{~cm}$. The walls and the vault were realised with pozzolana grout and mainly Tufo Lionato chunks. Some leucitite and pyroclastic fragments and bricks are also present. The lower part of the aqueduct walls has been realised digging a trench, while the upper part was probably realised above the ancient surface. The direction of the aqueduct is approximately $354^{\circ}$ North. It could not be precisely dated due to the lack of associated ceramic.

\subsection{The Sette Metri photogrammetric 3D model}

The two models (Fig. 3) produced results that were satisfactory for the purpose and globally complete. Both high-resolution models were produced with the Agisoft Metashape Professional software, following the same procedure articulated in the steps of alignment, alignment optimization, dense cloud and mesh generation, setting the high-quality parameter in each process. The first model was processed from 500 photos taken with an SLR camera, model Pentax K-x, with a resolution of $4288 \times 2848$. The second model was obtained from 60 photos (used all available exposures) taken by the Xiaomi Mi Note 10 smartphone, with a resolution of $12032 \times 9024$.

The alignment procedure generated a scattered point cloud and estimated the camera position for each photo; consider the fact that at the beginning the photos of the first model did not have any orientation information associated with them.

The alignment optimisation, based on the identification of a set of GCPs ( 6 for both models, acquired with GNSS survey, with millimetric accuracy), allowed to reach an accuracy value of 2 $\mathrm{cm}$ for the first model and $11 \mathrm{~cm}$ for the second.

Looking at the results in more detail, it can be seen that the model obtained from the first measurement campaign is more complete 

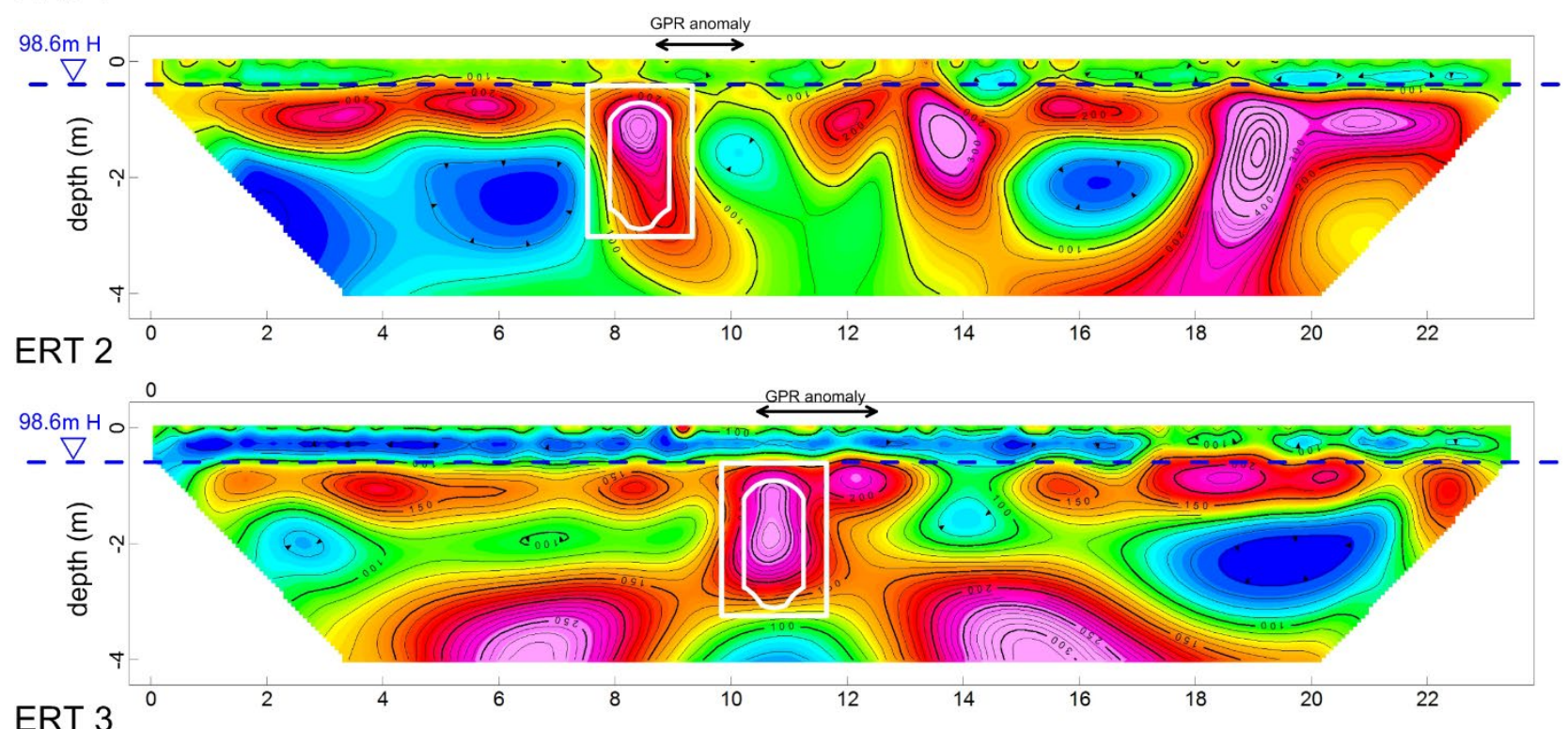

ERT 3
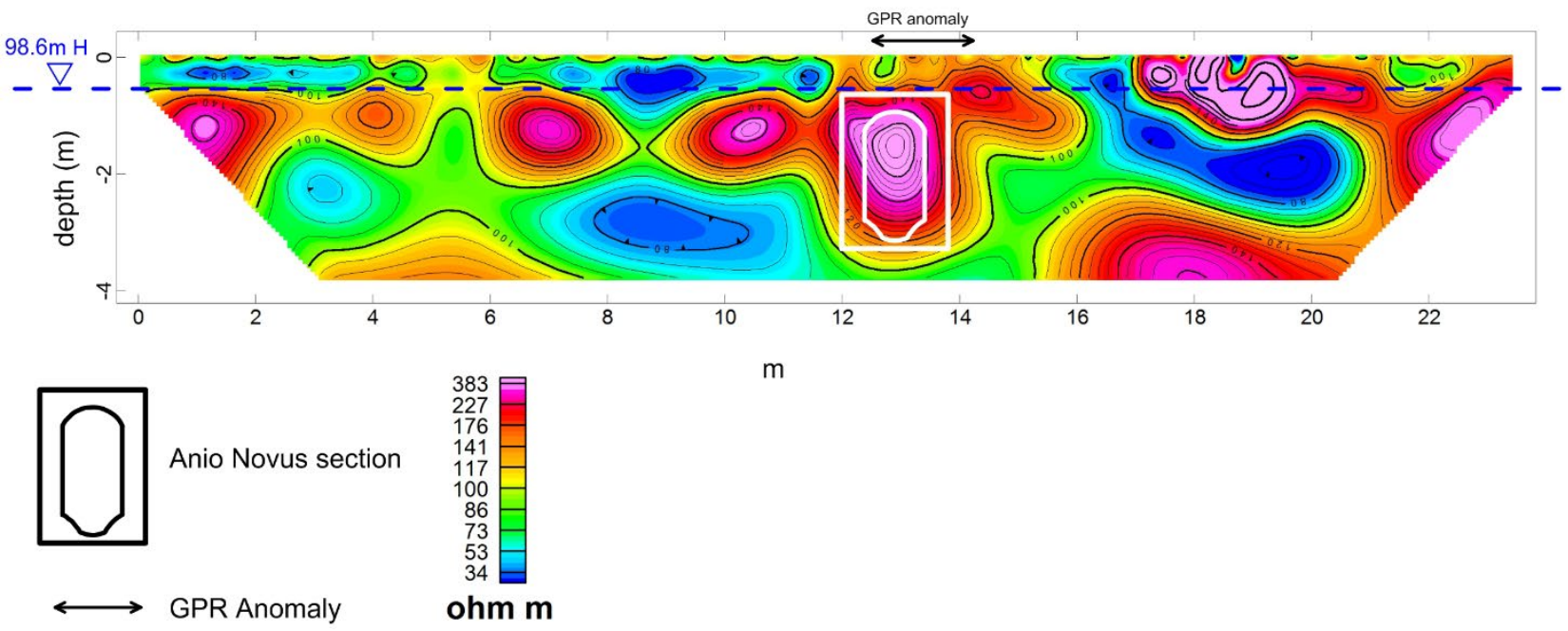

$\mathrm{m}$

Figure 7. The inversion results for the 3 profiles over the Anio Novus path

(i.e. with fewer gaps) and the GCP residuals (which therefore determine the accuracy) are much lower: about $2 \mathrm{~cm}$ for the first model, about $10 \mathrm{~cm}$ for the second model. The quality of the photos was better in the second model. It should be noted that in the first case a semi-professional camera was used with very low sunlight (the whole area in shadow) while in the second case a mobile phone with a 108-megapixel camera was used in the central hours of the day, therefore with more sunlight but with higher light and shadow contrasts. This last condition caused a problem with the average exposure, so the shots were repeated three times with automatic exposure and then with manual exposure in the shaded areas and then in the sunny areas.

All in all, the differences in the results could be due to the better correlation between the images acquired without contrasts of light and shadow, even if less sharp in quality. The difference could also be due to the better quality of the camera optics compared to the mobile phone optics, which have a much higher resolution.

Finally, the models were obtained through the generation of the dense point clouds (84 151757 points for the first model, 122 602206 points for the second). The meshes were generated based on these point clouds.
To extrapolate the elevation information, the digital elevation models were created, setting the meshes as input and deactivating the interpolation option. Starting from the DEM (Fig. 4), the elevation profiles of the sections identified on the threedimensional model were obtained (Fig. 5).

\subsection{The GPR results}

The survey was planned in order to intercept the prosecution of the Anio Novus aqueduct and the figure 6 shows an example of the analysis of both the $3 \mathrm{D}$ and $2 \mathrm{D}$ data.

The figure $6 \mathrm{~b}$, reports the radargram recorded at $\mathrm{X}=12 \mathrm{~m}$ where the anomaly due to the presence of the upper part of the aqueduct is clearly visible ( $\mathrm{Y}=30.5 \mathrm{~m}$; blue circle). It is consistent with a $2 \mathrm{~m}$ wide structure buried under $0.52 \mathrm{~m}$ of terrain. The abrupt interruption of the reflection of the top of local pozzolana (clearly visible at $1 \mathrm{~m}$ depth on the left of the anomaly) fits with the manner of construction of roman aqueducts. Besides, the magnitude of the reflected energy received at $1.1 \mathrm{~m}$ depth suggests the presence of a small part of void in the higher part of the internal aqueduct section. This strong reflection makes it easier to follow the pattern of the Avio Novus in the surveyed area 


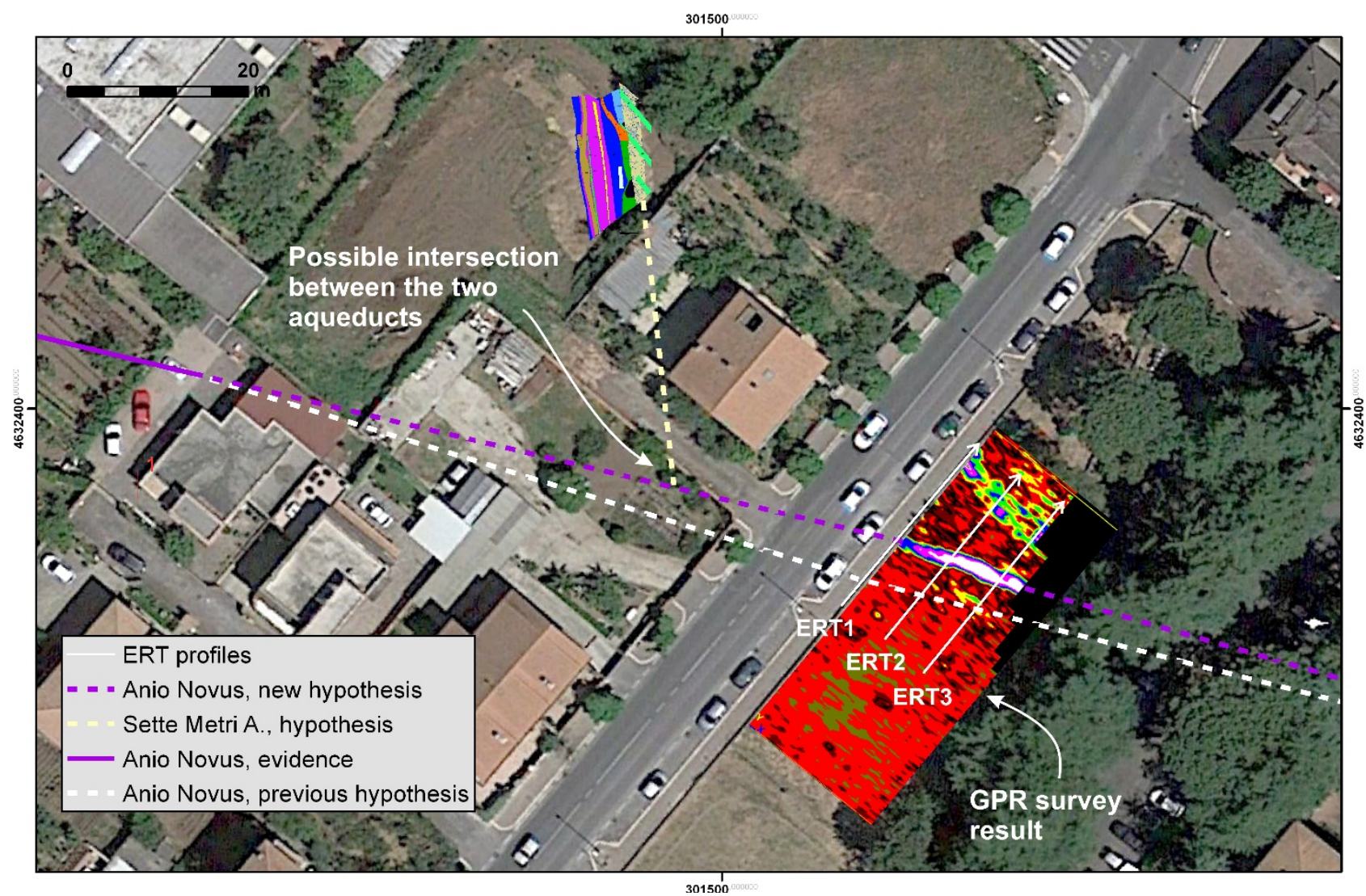

Figure 8. The possible intersection point between the Anio Novus and the Sette Metri aqueduct estimated on the base of archaeological and geophysical data

(see Fig. 6a). In the 3D area, the burial depth of the top part of the Anio Novus varies from 0.52 to $0.62 \mathrm{~m}$ along the eastward direction.

Observing figure 8, another alignment of reflected energy is visible at the same depth and elongated approximately perpendicular to the road. The presence of an inspection shaft in the surveyed area suggests this anomaly due to a sewer line.

\subsection{The ERT results}

The ERT inversion models are based on the joint inversion of apparent resistivity data, acquired on the ground surface using dipole-dipole and Wenner arrays. The inversion results for the 3 profiles are shown in figure 7. All profiles show a common resistivity layering that can be associated with variations in subsoil stratigraphy and the presence of ancient and modern anthropic structures.

Starting from the ground surface, all profiles show a $0.5 \mathrm{~m}$ thick first layer, characterized by a resistivity value less than $100 \mathrm{Ohm}$ $\mathrm{m}$. This superficial layer is followed by about $1 \mathrm{~m}$ thick resistive layer with a value up to $200 \mathrm{Ohm} \mathrm{m}$. A more conductive layer, starting from $1.5 \mathrm{~m}$ below ground surface, is present in all profiles but with different thicknesses up to $4 \mathrm{~m}$ below the surface for ERT 1, up to 2.5 and $3 \mathrm{~m}$ for ERT 2 and ERT 3 respectively. A deeper resistivity layer appears clearly along profile ERT2, characterized by high values of more than $200 \mathrm{Ohm} \mathrm{m}$, which is interpreted as the resistivity signature of a volcanic lithified tuff. This layer appears less clearly along profile ERT3. The presence of anthropic structures alters the natural alternating sequence of the layers. Some vertical high resistivity anomalies are present in the profiles: ERT1 shows three rounded anomalies centred at 8.5, 14 and $19 \mathrm{~m}$ along with the profile. ERT2 and ERT3 show one rounded anomaly centred at 11 and $13 \mathrm{~m}$ respectively.
The two anomalies in ERT1 at 14 and 19m along profile can be associated with the presence of modern anthropic service structures underneath the modern Via dei Sette Metri. The anomalies between 8 and $9.5 \mathrm{~m}$ for ERT1, 10 and $12 \mathrm{~m}$ for ERT2, 12 and $14 \mathrm{~m}$ for ERT3 are clearly correlated to the GPR main anomaly of figure 6 and then represent the same structure crosscut by the three vertical profiles; their geometry and common depth are compatible with the known section of the Anio Novus aqueduct in the survey area (Fig. 8) which is about $2.6 \mathrm{~m}$ high and $1.8 \mathrm{~m}$ wide. The three anomalies show a high resistivity value in their central part that could be the effect of a void space indicating that the aqueduct is not filled by debris or sediments.

\section{DISCUSSION}

The photogrammetric restitution of the Sette Metri aqueduct enabled the estimation of its southern path. The geophysical surveys were able to detect the path of the Anio Novus which in the previous hypotheses was placed around $4.5 \mathrm{~m}$ further South. These results allowed a precise estimation of the $2 \mathrm{D}$ intersection point between the two aqueducts (Fig. 8).

Height measurements at the lowest part of the Sette Metri specus, which would have been necessary to obtain a reliable estimate of the slope, could not be made for security reasons. However, it was possible to measure the height difference of the external part, which can provide a good indication of the slope, since the section of the whole unearthed stretch had the same shape and dimension, as is usual in Roman aqueducts for construction and hydraulic reasons. The top surface of the aqueduct decreases its orthometric height from south to north by about 25 centimetres in $11.5 \mathrm{~m}$ (from $97.30 \mathrm{~m}$ to $97.05 \mathrm{~m}$ ), which means a $2.17 \%$ slope. In the southern portion, the bottom of the internal ditch, where the water was flowing, was at about $95.21 \mathrm{~m}(97.30 \mathrm{~m}$ minus 


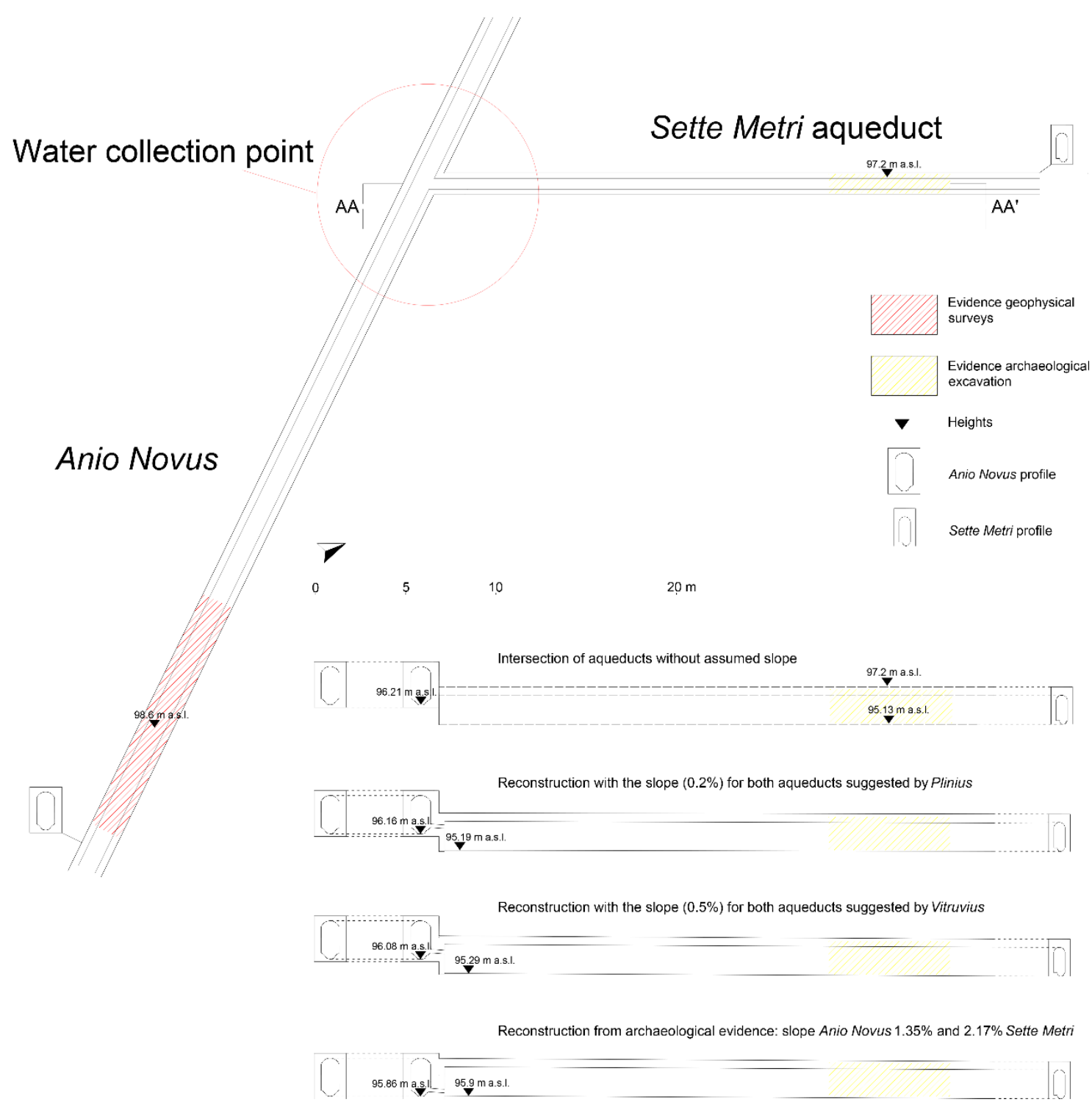

Figure 9. Map and profiles of the possible intersection between the Anio Novus and the Sette Metri aqueduct

$2.09 \mathrm{~m}$ ), thus after $32 \mathrm{~m}$ (the distance to the intersection point), the ditch bottom should be at $95.90 \mathrm{~m}$.

The detected surface of the Anio Novus is at an average of $98.6 \mathrm{~m}$ and the bottom of the internal specus might be at $96.21 \mathrm{~m}$. Since we know the height of the specus bottom of the Anio Novus around $280 \mathrm{~m}$ to the East $(99.7 \mathrm{~m}$, calculated at the bottom of the puteus, (fig. 1) we could estimate the slope of this stretch at around $1.35 \%$. The GPR height measurements (a decrease of $10 \mathrm{~cm}$ on a stretch of $14.5 \mathrm{~m}$, which results in a $0.7 \%$ slope), although less accurate, likewise suggest a substantial slope. The distance between the identified stretch of the Anio Novus and the intersection point is $26 \mathrm{~m}$. Thus, using the data from the puteus, the specus bottom would be at 95.86 (fig. 9) making the two specus virtually coincide at the intersection point. It must be noted that Plinius (Plin., N.H., XXXI, 31) and Vitruvius (Vitr., VIII, 6,1$)$ suggested slopes range between $0.2 \%$ and $0.5 \%$. These values would have increased the differences in height between the two specus at the intersection point (fig. 9). However, archaeological evidence has revealed that the slopes are quite variable even within the same aqueduct. It has been shown that the specus usually have a lower slope when it runs over the arches (in opere arcuate, between $0.1 \%$ and $0.2 \%$ ) compared to the underground (in rivus subterraneus) or substructured (in substructiones) stretches which could reach up to $4 \%$ (Alimonti et al., 2018; Baiocchi et al., 2020; Corbellini et al., 1917). The strong slope of the Sette Metri aqueduct can be explained by the constraints due to the collection point (the Anio Novus) and the termination point which might be the Roman villa reported to the north, near "Casalotto" (De Rossi, 1979).

These data strongly suggest that the Sette Metri aqueduct is a derivation of the Anio Novus and constitute a terminus post quem for the construction of the former, which should have come into use after the $52 \mathrm{CE}$.

As far as the heritage valorization is concerned, the realization of photogrammetric 3D models will also allow the visualization of the archaeological evidence by a general audience, since the excavated aqueduct has been buried again for conservative needs. The experience of these remains will contribute to the knowledge of the local history, enhancing the bond between the inhabitants and their landscape.

\section{ACKNOWLEDGEMENTS}

We wish to thank the owners of the field where the Sette Metri aqueduct was found, Vanina Mosca, Emiliano Mosca, Alessio 
Pianozza and the owner of the field where we performed the geophysical survey, the Agostinelli family. We also want to thank Letizia Rocci and Enza Restivo of the Soprintendenza Speciale di Roma for their support during the research.

\section{REFERENCES}

Alessandri, L., Baiocchi, V., Del Pizzo, S., Di Ciaccio, F., Onori, M., Rolfo, M.F., Troisi, S., 2020. A flexible and swift approach for 3D image-based survey in a cave. Appl. Geomatics. https://doi.org/10.1007/s12518-020-00309-4

Alimonti, C., Baiocchi, V., Bonanotte, G., Molnar, G., 2018. Measuring and leveling roman aqueducts to estimate their flows, in: 2018 Metrology for Archaeology and Cultural Heritage (MetroArchaeo). pp. 527-531. https://doi.org/10.1109/MetroArchaeo43810.2018.13581

Ashby, T., 1935. The Aqueducts of Ancient Rome. Oxford.

Baiocchi, V., Alimonti, C., Bonanotte, G., Molnar, G., 2020. Geomatic measurement of "New Aniene" and "Claudia" roman aqueducts for flows estimation. IOP Conf. Ser. Mater. Sci. $\quad$ Eng. 12078. https://doi.org/10.1088/1757-899x/949/1/012078

Baiocchi, V., Camuccio, P., Zagari, M., Ceglia, A., Del Gobbo, S., Purri, F., Cipollini, L., Mezzapesa, M., Liso, L., Vatore, F., 2017. Development of a geographic database of a district area in open source environment. Geoing. Ambient. e Mineraria 151, 97-101.

Barzaghi, R., Borghi, A., Carrion, D., Sona, G., 2007. Refining the estimate of the Italian quasi-geoid. Boll. di Geod. e Sci. Affin. Anno LXVI, 145-160.

Blanco, D., Sebastiani Del Grande, P., 2019. Studio preliminare sul percorso degli acquedotti romani tra l'area di Gregna di Sant'Andrea e le Capannelle, in: Fischetti, A.L., Attema, P.A.J. (Eds.), Alle Pendici Dei Colli Albani. Dinamiche Insediative e Sviluppo Del Territorio Barkhuis, Groningen, pp. 157-171.

Caroti, G., Martínez-Espejo Zaragoza, I., Piemonte, A., 2015. ACCURACY ASSESSMENT IN STRUCTURE FROM MOTION 3D RECONSTRUCTION FROM UAV-BORN IMAGES: THE INFLUENCE OF THE DATA PROCESSING METHODS. Int. Arch. Photogramm. Remote Sens. Spat. Inf. Sci. XL-1/W4, 103-109. https://doi.org/10.5194/isprsarchives-XL-1-W4-103-2015

Constable, S.C., Parker, R.L., Constable, C.G., 1987. Occam's inversion: A practical algorithm for generating smooth models from electromagnetic sounding data. GEOPHYSICS 52, 289-300. https://doi.org/10.1190/1.1442303

Corbellini, G., Reina, V., Ducci, G., 1917. Livellazione degli antichi acquedotti romani. Tipografia della Reale Accademia dei Lincei.

De Rossi, G.M., 1979. Bovillae, Forma Italiae 26. Firenze.

deGroot-Hedlin, C., Constable, S., 1990. Occam's inversion to generate smooth, two-dimensional models from magnetotelluric data. GEOPHYSICS 55, 1613-1624. https://doi.org/10.1190/1.1442813

Lanciani, R.A., 1880. Topografia di Roma antica: i commentarii di Frontino intorno le acque e gli acquedotti: silloge epigrafica aquaria. Roma.

Loke, M.H., 2012. Tutorial: 2-D and 3-D Electrical Imaging Surveys. Geotomo software. Malaysia.

Masiero, A., Chiabrando, F., Lingua, A.M., Marino, B.G., Fissore, F., Guarnieri, A., Vettore, A., 2019. 3D MODELING OF GIRIFALCO FORTRESS. Int. Arch.
Photogramm. Remote Sens. Spat. Inf. Sci. XLII-2/W9, 473-478. https://doi.org/10.5194/isprs-archives-XLII-2W9-473-2019

Morelli, G., Labrecque, D.J., 1996. Advances in ERT inverse modelling. Eur. J. Environ. Eng. Geophys. 1, 171-186.

Rete GNSS della Regione Lazio, 2018.

Ullman, S., Brenner, S., 1979. The interpretation of structure from motion. Proc. R. Soc. London. Ser. B. Biol. Sci. 203, 405-426. https://doi.org/10.1098/rspb.1979.0006 